\title{
Stabilities of nanohydrated thymine radical cations: insights from multiphoton ionization experiments and ab initio calculations $^{\star}$
}

\author{
Rahul Pandey ${ }^{1}$, Mathieu Lalande ${ }^{2}$, Michal Ryszka ${ }^{1}$, Paulo Limão-Vieira ${ }^{3}$, Nigel J. Mason ${ }^{1}$, \\ Jean-Christophe Poully ${ }^{2}$, and Samuel Eden ${ }^{1, a}$ \\ 1 School of Physical Sciences, The Open University, Walton Hall, Milton Keynes, MK7 6AA, UK \\ 2 CIMAP, UMR 6252 (CEA/CNRS/ENSICAEN/Université de Caen Normandie), Caen, France \\ 3 Laboratório de Colisões Atómicas e Moleculares, CEFITEC, Departamento de Física, FCT - Universidade Nova \\ de Lisboa, 2829-516 Caparica, Portugal
}

Received 30 December 2016 / Received in final form 21 April 2017

Published online 11 July 2017

(c) The Author(s) 2017. This article is published with open access at Springerlink.com

\begin{abstract}
Multi-photon ionization experiments have been carried out on thymine-water clusters in the gas phase. Metastable $\mathrm{H}_{2} \mathrm{O}$ loss from $\mathrm{T}^{+}\left(\mathrm{H}_{2} \mathrm{O}\right)_{n}$ was observed at $n \geq 3$ only. Ab initio quantum-chemical calculations of a large range of optimized $\mathrm{T}^{+}\left(\mathrm{H}_{2} \mathrm{O}\right)_{n}$ conformers have been performed up to $n=4$, enabling binding energies of water to be derived. These decrease smoothly with $n$, consistent with the general trend of increasing metastable $\mathrm{H}_{2} \mathrm{O}$ loss in the experimental data. The lowest-energy conformers of $\mathrm{T}^{+}\left(\mathrm{H}_{2} \mathrm{O}\right)_{3}$ and $\mathrm{T}^{+}\left(\mathrm{H}_{2} \mathrm{O}\right)_{4}$ feature intermolecular bonding via charge-dipole interactions, in contrast with the purely hydrogen-bonded neutrals. We found no evidence for a closed hydration shell at $n=4$, also contrasting with studies of neutral clusters.
\end{abstract}

\section{Introduction}

The response of DNA constituents to ionizing radiation is of major interest in order to understand the molecular mechanisms responsible for biological damage in radiotherapy and environmental radiation fields. Although studying DNA bases in the gas phase can lead to relatively clear interpretations, it represents a major step away from condensed macromolecular systems. Complementary studies of nucleotides [1], base pairs [2], and hydrated clusters $[3-5]$ can enable closer analogies to be drawn with irradiated biological material. However, as cluster sources generally produce a broad distribution of conformations and sizes, characterizing the precursor of a specific product can present a significant challenge in experiments probing radiation-induced processes in clusters. Mass spectrometry measurements of metastable product ions can help to address this challenge by simultaneously defining the ion cluster mass before and after dissociation. Furthermore, they can provide information on binding energies as the microsecond-order time delay implies that the vibrational energy of the cluster ion was very close to the relevant dissociation barrier. Metastable dissociation experiments have therefore played an important role in cluster research for many years [6-8], notably by

\footnotetext{
* Contribution to the Topical Issue "Dynamics of Systems at the Nanoscale", edited by Andrey Solov'yov and Andrei Korol.

${ }^{a}$ e-mail: s.p.eden@open.ac.uk
}

means of UV irradiation $[9,10]$. Here we investigate the stabilities of nanohydrated thymine radical cations based on metastable dissociation measurements and ab initio calculations.

The majority of previous UV irradiation experiments on thymine have probed the relaxation dynamics following access to quite low vibrational levels of its optically bright $S_{2}$ state, for example pumping with the third harmonic of Ti-sapphire laser $(4.65 \mathrm{eV}$ compared with the calculated $S_{2}$ origin of at $4.49 \mathrm{eV}$ [11]). In the present nstimescale UV multiphoton ionization (MPI) experiments thymine is excited at a photon energy of $5.64 \mathrm{eV}(220 \mathrm{~nm})$, where significant vibrational excitation increases the range of possible relaxation pathways after ionization. In addition to proton, hydrogen and hydride transfers that have been observed [12,13] or predicted [14] in DNA building blocks, diverse fragmentation and evaporation processes can occur. While the decrease in ionization energy of thymine with nanohydration has been experimentally and theoretically studied by several groups $[15,16]$, scarce reports can be found on the structure and decay processes of thymine-water cluster ions [10]. This paper investigates the metastable evaporation of one water molecule from UV multiphoton ionized thymine-water clusters by mass spectrometry. Moreover, we have performed the most extensive set of ab initio quantum-chemical calculations of optimized hydrated thymine radical cation conformers to date. The relative intensities of the metastable signals 


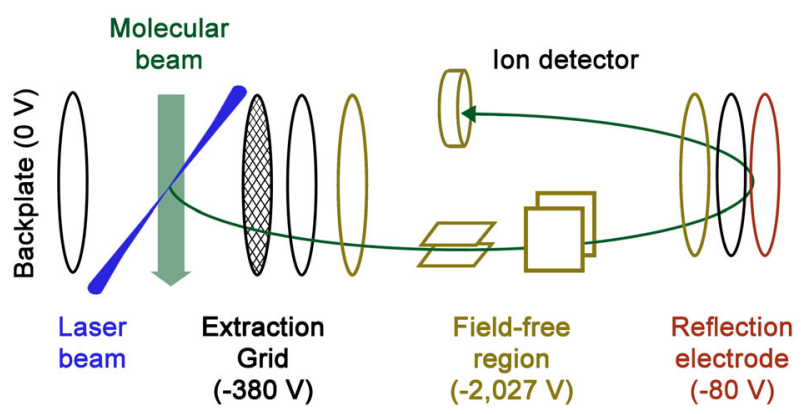

Fig. 1. Schematic diagram of the reflectron mass spectrometer.

in the MPI experiments are discussed in the context of the calculated binding energies of the precursor cluster ions.

\section{Experimental}

The experimental system has been described in previous publications $[5,17,18]$. Briefly, argon carrier gas (1.1 bar) seeded with sublimated thymine (Sigma-Aldrich with stated purity $\geq 99 \%$ ) expanded continuously through a $50 \mu \mathrm{m}$ diameter pinhole into a pumped chamber $\left(1000 \mathrm{ls}^{-1}\right)$ to form a supersonic jet. Water vapor from a heated reservoir could be introduced to the carrier gas via a valve. The powder temperature $\left(250^{\circ} \mathrm{C}\right)$ was comparable with or lower than those applied in previous massspectrometry and IR spectroscopy experiments that reported no evidence for thermally driven decomposition, isomerization, tautomerization, or reactivity in thymine following sublimation in an inert gas [19]. The jet passed through a skimmer into a second pumped chamber and crossed an Nd:YAG pumped and frequency doubled dye laser beam (Continuum Powerlight II 8000 - Sirah CobraStretch, repetition rate $10 \mathrm{~Hz}$, pulse width $7 \mathrm{~ns}$, pulse energy 100-2000 $\mu \mathrm{J}$, wavelength $219-277 \mathrm{~nm}$ ). The resulting ions were detected using a reflectron time-of-flight (TOF) mass spectrometer (supplied by KORE Technology and shown schematically in Fig. 1). The pre-amplified ion signals were timed using a Fast Comtec Pr887 time-todigital conversion (TDC) card. The data acquisition system was based on a LabView application interfacing with the TDC card and a laser pulse energy meter (Spectrum Detector $S P J-D-8)$. A convex lens on a slider was used to control the laser spot diameter at the crossing point with the molecular beam and the average laser pulse energy was adjusted using the delay between the pulses triggering the xenon flash lamps and the $Q$-switch of the Nd:YAG laser.

\section{Theoretical methods}

The central aim of the theoretical work was to obtain binding energies for single $\mathrm{H}_{2} \mathrm{O}$ loss from nanohydrated thymine radical cations $\mathrm{T}^{+}\left(\mathrm{H}_{2} \mathrm{O}\right)_{n}(n=1-4)$. We chose the uMP2 $/ 6-31+\mathrm{g}(d, p)$ level of theory as this has been demonstrated to provide enthalpy changes for water evaporation from nanohydrated pyridine in very good agreement with experimental values [20]. All calculations have been performed with the Gaussian 09 package [21].
We first calculated the adiabatic ionization energies (IE) as the difference between the zero-point vibrational energy (ZPE) corrected ground-state potential energies of the lowest-energy optimized conformers of $\mathrm{T}\left(\mathrm{H}_{2} \mathrm{O}\right)_{n}$ and $\mathrm{T}^{+}\left(\mathrm{H}_{2} \mathrm{O}\right)_{n}$. Basis set superposition errors (BSSE) were calculated for $n=1$ and found to be small; the IE changed from $8.72 \mathrm{eV}$ to $8.75 \mathrm{eV}$. Moreover, these corrections were computationally unaffordable for $n>1$ so the results presented here have not been BSSE-corrected. Table 1 compares the present IEs with earlier calculations [15] and with experimental photoionization [22-24] and electron impact ionization results [25]. Despite the lower level of theory we used compared to Khistyaev et al. [15], there is a fair agreement with their results as well with the experimental data. This provides further support for applying this level of theory and indicates that it is suitable for studying larger clusters for which higher-level methods such as CCSD are not computationally affordable. We define water binding energy (BE) as the difference between the ZPE corrected ground-state potential energies of the optimized conformers of $\mathrm{T}^{+}\left(\mathrm{H}_{2} \mathrm{O}\right)_{n}$ and $\mathrm{T}^{+}\left(\mathrm{H}_{2} \mathrm{O}\right)_{n-1}+$ $\mathrm{H}_{2} \mathrm{O}$. We used chemical intuition as well as previously reported structures to build the initial geometries and optimized them with the default algorithm. No imaginary frequency was found for all conformers studied, showing that they are true minima of the potential energy surface. For radical cations, we found that spin contamination by higher spin-states was negligible since the spin operator value after annihilation was 0.7573 on average and always lower than 0.763 .

For neutral species, three conformers were found for $n=1-3$ and two for $n=4$. For radical cations, we considered 4, 11, 17 and 12 conformers for $n=1,2,3$ and 4, respectively. Only the diketo tautomer of neutral thymine was considered, since it was established by previous work as the only one present in supersonic jets of isolated [27] or nanohydrated molecules [4,28]. After multiphoton ionization of these species, tautomerization might occur by overcoming barriers calculated to be on the order of $1 \mathrm{eV}$ by DFT methods [29] but since these conformers are predicted to have very similar energies compared to diketo tautomers, their water binding energy will also be similar. The average of all possible evaporations (with minimum rearrangement) for a given conformer was calculated, and the average of all conformers gave the average binding energy $\left(\mathrm{BE}_{\mathrm{ave}}\right)$. The minimum binding energy $\left(\mathrm{BE}_{\min }\right)$ is the difference between the lowest-energy conformers of $\mathrm{T}^{+}\left(\mathrm{H}_{2} \mathrm{O}\right)_{n}$ and $\mathrm{T}^{+}\left(\mathrm{H}_{2} \mathrm{O}\right)_{n-1}+\mathrm{H}_{2} \mathrm{O}$. For $n=1$, we obtain a value of $0.77 \mathrm{eV}$, slightly higher than that measured by Ibrahim et al. [20] for the pyridine radical cation $(0.59 \mathrm{eV})$ and consistent with water being bound to an $\mathrm{NH}$ group in both cases and to the adjacent $\mathrm{C}=\mathrm{O}$ group in thymine (see Fig. 3).

\section{Results and discussion}

\subsection{MPI of nanohydrated thymine}

Figure 2 shows MPI $\left(220 \mathrm{~nm}, 8 \times 10^{7} \mathrm{~W} \mathrm{~cm}^{-2}\right)$ production of hydrated thymine monomer ions, while larger 
Table 1. Calculated ionization energies (IE; adiabatic zero point corrected energy difference between the lowest-energy optimized ionic and neutral conformations; MP2/6-31 $\mathrm{g}(d, p)$ level) of thymine-water clusters compared with previous photoionization [15,22-24] and electron impact [25] measurements.

\begin{tabular}{|c|c|c|c|}
\hline \multirow{2}{*}{ Neutral species } & \multicolumn{2}{|c|}{ Calculated adiabatic IE (eV) } & \multirow{2}{*}{ Experimental IE $(\mathrm{eV})^{*}$} \\
\hline & Present work & Khistyaev et al. [15] & \\
\hline \multirow{5}{*}{ Thymine } & \multirow{5}{*}{9.08} & \multirow{5}{*}{8.90} & $8.9178 \pm 0.001[24]$ \\
\hline & & & $8.82 \pm 0.03[22]$ \\
\hline & & & $8.85 \pm 0.05[15]$ \\
\hline & & & $8.90 \pm 0.05[23]$ \\
\hline & & & $9.15 \pm 0.15[25]$ \\
\hline \multirow{3}{*}{$\mathrm{T}\left(\mathrm{H}_{2} \mathrm{O}\right)$} & \multirow{3}{*}{8.72} & \multirow{3}{*}{8.51} & $8.75 \pm 0.05[23]$ \\
\hline & & & $8.60 \pm 0.05[15]$ \\
\hline & & & $8.85 \pm 0.15[25]$ \\
\hline \multirow{3}{*}{$\mathrm{T}\left(\mathrm{H}_{2} \mathrm{O}\right)_{2}$} & \multirow{3}{*}{8.57} & \multirow{3}{*}{8.52} & $8.6 \pm 0.1[23]$ \\
\hline & & & $8.55 \pm 0.05[15]$ \\
\hline & & & $8.65 \pm 0.15[25]$ \\
\hline \multirow{3}{*}{$\mathrm{T}\left(\mathrm{H}_{2} \mathrm{O}\right)_{3}$} & \multirow{3}{*}{8.34} & \multirow{3}{*}{8.35} & $8.6 \pm 0.1[23]$ \\
\hline & & & $8.40 \pm 0.05[15]$ \\
\hline & & & $8.50 \pm 0.15[25]$ \\
\hline $\mathrm{T}\left(\mathrm{H}_{2} \mathrm{O}\right)_{4}$ & 8.30 & - & - \\
\hline
\end{tabular}

* Choi et al. [24], Jochims et al. [22], Khistyaev et al. [15] and Belau et al. [23] interpreted their photoionization data as providing adiabatic IEs. Kim et al. [25] noted that their measurements for isolated nucleobases match Hush and Cheung's [26] photoelectron spectroscopic results $(9.14 \mathrm{eV}$ for thymine), indicating that their IEs can be regarded as vertical.

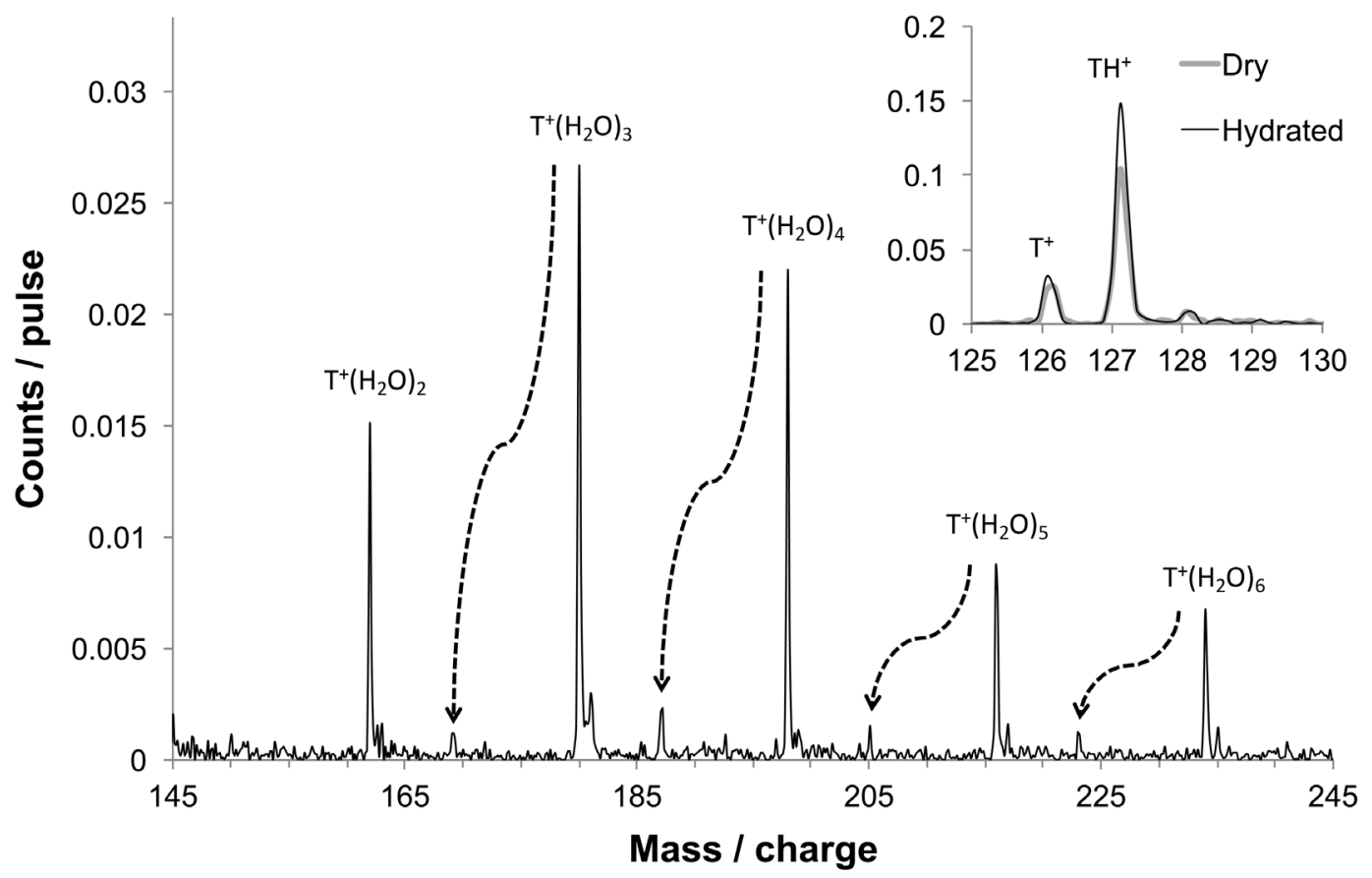

Fig. 2. MPI (220 nm, average fluence $8 \times 10^{7} \mathrm{~W} \mathrm{~cm}^{-2}$, water $50{ }^{\circ} \mathrm{C}, \mathrm{Ar} 1.1$ bar $)$ mass spectrum of thymine-water clusters. The dotted arrows signify metastable $\mathrm{H}_{2} \mathrm{O}$ loss (note that the mass calibration does not apply to these peaks). The insert compares a detail of the mass spectrum with an equivalent measurement recorded in dry conditions (before opening the valve to add water vapor to the expansion). 


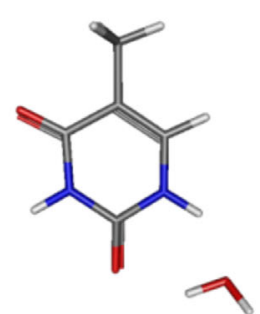

$\mathrm{T}\left(\mathrm{H}_{2} \mathrm{O}\right)$

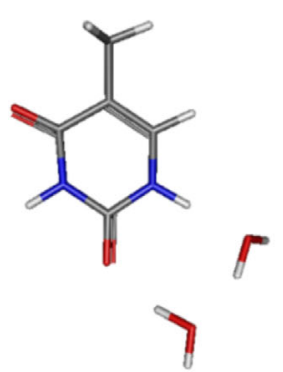

$\mathrm{T}\left(\mathrm{H}_{2} \mathrm{O}\right)_{2}$

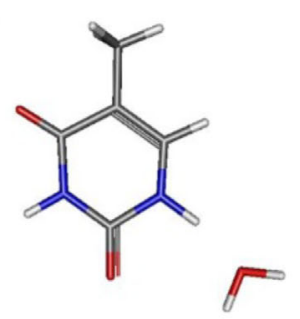

$\mathrm{T}^{+}\left(\mathrm{H}_{2} \mathrm{O}\right), 1$

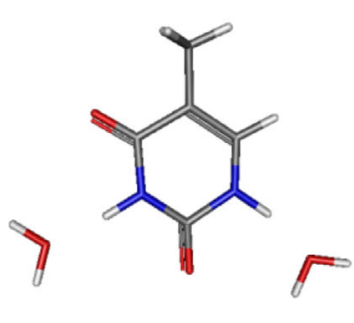

$\mathrm{T}^{+}\left(\mathrm{H}_{2} \mathrm{O}\right)_{2}, 1$

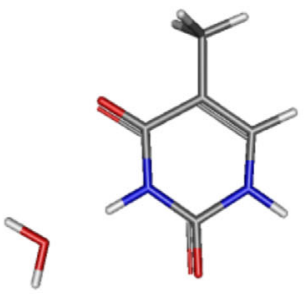

$2, \Delta \mathrm{E}=106 \mathrm{meV}$

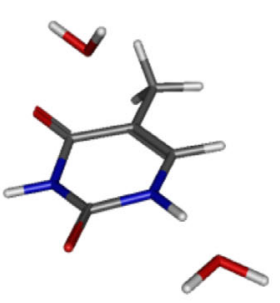

$2, \Delta \mathrm{E}=26 \mathrm{meV}$

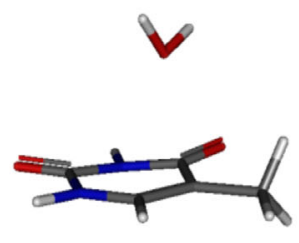

3, $\Delta \mathrm{E}=142 \mathrm{meV}$

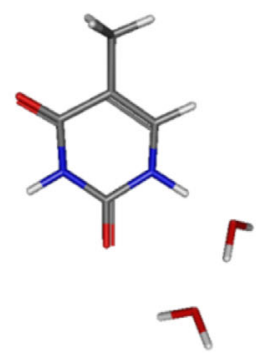

$3, \Delta \mathrm{E}=60 \mathrm{meV}$

Fig. 3. Structures of the lowest-energy conformers of $\mathrm{T}\left(\mathrm{H}_{2} \mathrm{O}\right)_{n}$ and $\mathrm{T}^{+}\left(\mathrm{H}_{2} \mathrm{O}\right)_{n}(n=1-2)$, optimized at the MP2/6-31+g $(d, p)$ level. Relative $\mathrm{T}^{+}\left(\mathrm{H}_{2} \mathrm{O}\right)_{n}$ conformer energies $\left(\Delta E\right.$, zero-point vibrational energy corrected) are indicated. The $\mathrm{T}^{+}\left(\mathrm{H}_{2} \mathrm{O}\right)_{n}$ conformers are labeled $1-3$ in order of increasing $\Delta E$.

complexes were observed up to $\mathrm{m} / \mathrm{z} 288\left(\mathrm{~T}_{2}^{+}\left(\mathrm{H}_{2} \mathrm{O}\right)_{2}\right.$ or $\left.\mathrm{T}^{+}\left(\mathrm{H}_{2} \mathrm{O}\right)_{9}\right)$. Previous MPI experiments $(266 \mathrm{~nm}, 7 \times$ $\left.10^{5} \mathrm{~W} \mathrm{~cm}^{-2}\right)$ have produced $\mathrm{T}^{+}\left(\mathrm{D}_{2} \mathrm{O}\right)_{n}$ and $\mathrm{T}_{2}^{+}\left(\mathrm{D}_{2} \mathrm{O}\right)_{n}$ with $n$ up to 10 and 6 , respectively [10]. The insert in Figure 2 compares the signals for thymine ${ }^{+}$and protonated thymine $\left(\mathrm{TH}^{+}\right)$recorded in dry and hydrated expansion conditions (before and after opening the valve to the heated water reservoir, respectively). Prior to the $d r y$ measurement, the nozzle and the carrier gas line were pumped overnight using a scroll pump and then purged for two hours in a flow of argon carrier gas while the powder temperature was increased and stabilized. Water is transparent at $220 \mathrm{~nm}$ [30] and thermochemical calculations have shown that proton transfer from $\mathrm{T}^{+}$to $\mathrm{T}$ in a dimer cation is exothermic [31]. Therefore, the present $\mathrm{TH}^{+}$signals are attributed to the dissociation of thymine dimer ions (or possibly larger thymine cluster ions), with or without associated water molecules. Due to the relatively weak binding between thymine and water molecules [3], $\mathrm{T}_{m}^{+}$(where $m$ is the number of thymine molecules) fissure within a hydrated cluster is expected to involve extensive water loss. Accordingly, the weak features with one $\mathrm{m} / \mathrm{z}$ unit above the $\mathrm{T}^{+}\left(\mathrm{H}_{2} \mathrm{O}\right)_{n}$ values $(12 \pm 1 \%$ of these peaks) can be attributed to approximately equal proportions of $\mathrm{TH}^{+}\left(\mathrm{H}_{2} \mathrm{O}\right)_{n}$ and cluster ions containing ${ }^{13} \mathrm{C}$ isotopes $(6 \%)$ [32].

Comparing ion signals in dry and hydrated conditions can provide insights into the neutral excited state dynamics that take place during the present MPI processes. Previous dynamical calculations and time-resolved spectroscopic measurement on isolated nucleobases have revealed a great deal of information on the relaxation pathways from their optically bright $S_{2}$ states [33,34].
Internal conversion to the electronic ground state (either directly or via $S_{1}$ states of mainly $n \pi^{*}$ character) dominates $S_{2}\left(\pi \pi^{*}\right)$ deactivation although intersystem crossing to long-lived triplet states has also been reported. Kang et al.'s [33] transient ionization experiments revealed a slow decay component of thymine with a time constant of $>100$ ps. Similarly, He et al.'s [35] pump-probe measurements (267 nm pump) showed a dark state with a lifetime of several tens to hundreds of ns, depending on the probe wavelength (220-273 nm). Kang et al. [33] assigned the slow decay to ionization from a triplet state, while recent double resonance spectroscopy experiments and ab initio calculations support a ${ }^{3} \pi \pi^{*}$ character [36]. He et al. [35] reported that hydration significantly repressed access to the long-lived dark state. Therefore, the fact that thymine radical ion production was not suppressed due to the formation of thymine-water clusters (Fig. 2 inset) provides a strong indicator that the dominant MPI pathways in the present experiments do not involve ionization from triplet states. On the contrary, the total MPI signal (summing all counts from cluster ions, $\mathrm{TH}^{+}, \mathrm{T}^{+}$, and fragment ions with $\mathrm{m} / \mathrm{z}$ lower than $\mathrm{T}^{+}$) increased by $56 \pm 10 \%$. This increase can be attributed partially to the reduction in ionization energy due to clustering with water (see the calculated and experimental data in Tab. 1). Furthermore, the predicted shifts in the vertical excitation energies of $S_{2}$ (calculated red shift of $0.02-0.19 \mathrm{eV}$ ) and $S_{1}$ (blue shift of $0.21-0.80 \mathrm{eV}$ ) due to hydration [37] are expected to affect MPI efficiency.

Figure 2 shows a series of peaks in between the $\mathrm{T}^{+}\left(\mathrm{H}_{2} \mathrm{O}\right)_{n}(2 \leq n \leq 6)$ features. Comparisons between calculated and measured flight times enabled these peaks to be assigned to metastable loss of a single $\mathrm{H}_{2} \mathrm{O}$ molecule 
Table 2. Signals for metastable single $\mathrm{H}_{2} \mathrm{O}$ loss from $\mathrm{T}^{+}\left(\mathrm{H}_{2} \mathrm{O}\right)_{n}$ expressed as percentages of the signals for the original cluster ions. The signal-to-noise ratio was insufficient to obtain a useful result for metastable $\mathrm{H}_{2} \mathrm{O}$ loss from $\mathrm{T}^{+}\left(\mathrm{H}_{2} \mathrm{O}\right)$.

\begin{tabular}{cc}
\hline $\begin{array}{c}\text { Original cluster } \\
\text { ion formula }\end{array}$ & $\begin{array}{c}\text { Metastable } \mathrm{H}_{2} \mathrm{O} \text { loss signal } \\
\text { /original cluster ion signal }\end{array}$ \\
\hline $\mathrm{T}^{+}\left(\mathrm{H}_{2} \mathrm{O}\right)_{6}$ & $18.6 \pm 5.4 \%$ \\
$\mathrm{~T}^{+}\left(\mathrm{H}_{2} \mathrm{O}\right)_{5}$ & $12.5 \pm 3.3 \%$ \\
$\mathrm{~T}^{+}\left(\mathrm{H}_{2} \mathrm{O}\right)_{4}$ & $17.5 \pm 2.6 \%$ \\
$\mathrm{~T}^{+}\left(\mathrm{H}_{2} \mathrm{O}\right)_{3}$ & $8.1 \pm 1.4 \%$ \\
$\mathrm{~T}^{+}\left(\mathrm{H}_{2} \mathrm{O}\right)_{2}$ & No metastable peak* \\
\hline
\end{tabular}

* To be hidden by the background level in Figure 2, the metastable $\mathrm{H}_{2} \mathrm{O}$ loss signal must be $<3.7 \%$ of the $\mathrm{T}^{+}\left(\mathrm{H}_{2} \mathrm{O}\right)_{2}$ signal.

from $\mathrm{T}^{+}\left(\mathrm{H}_{2} \mathrm{O}\right)_{n}(3 \leq n \leq 6)$ complexes in the field-free region (FFR) of the mass spectrometer (1.5-21.4 $\mu$ s after ionization) Metastable dissociation events that take place before the ions have reached the FFR or in the reflecting part of the mass spectrometer lead to a broad distribution of modified flight times and hence do not manifest themselves as distinct peaks in a mass spectrum. The flight-time calculations were based on a simple model of the electric fields in between the various electrodes in the mass spectrometer [38]. Different possible dissociations in the FFR were tested iteratively until a good match was achieved between the calculated and measured flight times. The intensities of the metastable peaks are listed as percentages of the respective parent (or original) cluster ion signals in Table 2. The signal-tonoise ratio was insufficient to obtain a useful result for metastable $\mathrm{H}_{2} \mathrm{O}$ loss from $\mathrm{T}^{+}\left(\mathrm{H}_{2} \mathrm{O}\right)$ and there is no clear peak for $\mathrm{H}_{2} \mathrm{O}$ loss from $\mathrm{T}^{+}\left(\mathrm{H}_{2} \mathrm{O}\right)_{2}$. Indeed, the most striking result in Table 2 is an increase of $>400 \%$ in metastable $\mathrm{H}_{2} \mathrm{O}$ loss relative to parent $\mathrm{T}^{+}\left(\mathrm{H}_{2} \mathrm{O}\right)_{n}$ detection over the cluster size range $n=2-4$. Kim et al. [10] observed an increase of around $100 \%$ in this cluster size range; the more pronounced effect in the present work may be linked to differences in the ionizing laser conditions applied in the two experiments. Increased metastable dissociation of clusters is widely viewed as a possible indicator of a lower energy threshold for the removal of a single molecule, helping to recognize particularly stable cluster sizes (so-called magic numbers often linked to shell structures) [39]. Kim et al. [10] observed a particular increase in metastable $\mathrm{H}_{2} \mathrm{O}$ loss for $n \geq 4$ and stated that this might indicate that the first solvation shell around the thymine radical cation is composed of four water molecules. Belau et al.'s [23] single-photon ionization mass spectrum of a supersonic beam containing various clusters comprising thymine, water, and/or adenine molecules only showed clear $\mathrm{T}^{+}\left(\mathrm{H}_{2} \mathrm{O}\right)_{n}$ peaks up to $n=4$. At a first look, this appears to support Kim et al.'s [10] shell closure proposal based on their metastable dissociation results. However, an equivalent direct consideration Kim et al.'s [10] 2-photon ionization mass spectra reveals no distinct step in sequential peak heights for $\mathrm{T}^{+}\left(\mathrm{D}_{2} \mathrm{O}\right)_{n}$ in the range $n=1-10$. Similarly, Kim et al.'s $[10,40]$ electron im- pact ionization and 2-photon ionization mass spectra of thymine-water clusters did not provide any suggestion of shell structures up to $n=6$ (above which the singly hydrated cation peaks overlap with the $\mathrm{T}_{2}^{+}\left(\mathrm{H}_{2} \mathrm{O}\right)_{n}$ peaks). This highlights the main limitation of directly comparing cluster ion peak heights in a mass spectrum as a means to extract information about relative stabilities: the peak heights reflect both the abundance of neutral clusters in the target and the stability of the ionized clusters. By contrast, mass spectrometry measurements of metastable product ions simultaneously define the ion cluster mass before and after dissociation. We have carried out ab initio quantum-chemical calculations of optimized $\mathrm{T}^{+}\left(\mathrm{H}_{2} \mathrm{O}\right)_{n}$ conformers in order to see if the water binding energies can help to explain the experimental metastable evaporation results.

\subsection{Ab initio quantum-chemical calculations on nanohydrated thymine neutrals and radical cations}

Figures 3-5 show the lowest-energy optimized structures of $\mathrm{T}\left(\mathrm{H}_{2} \mathrm{O}\right)_{n}$ and $\mathrm{T}^{+}\left(\mathrm{H}_{2} \mathrm{O}\right)_{n}(n=1-4)$. We also depict the $\mathrm{T}^{+}\left(\mathrm{H}_{2} \mathrm{O}\right)_{n}$ conformers within $100 \mathrm{meV}$ of the minimum ZPE corrected energy, as well as two additional higher-energy conformers for $n=1$. This energy has been shown to be the typical uncertainty of MP2 methods in predicting interaction energies of biologically relevant noncovalent clusters [41]. The neutral structures are consistent with previous experiments for $n=1$ [34] and calculations for $n=1,2,[28,42]$ and 4 [43]. Close et al. [44] found a different lowest-energy $\mathrm{T}\left(\mathrm{H}_{2} \mathrm{O}\right)_{3}$ conformer than the one in Figure 4 which is $9 \mathrm{~kJ} / \mathrm{mol}(93 \mathrm{meV})$ higher according to their DFT calculations.

To the best of our knowledge, no spectroscopic studies of $\mathrm{T}^{+}\left(\mathrm{H}_{2} \mathrm{O}\right)_{n}$ are available in the literature and only two theoretical studies have been reported. Kim's [29] optimized geometry of the lowest-energy conformer of $\mathrm{T}^{+}\left(\mathrm{H}_{2} \mathrm{O}\right)$ is similar to the present result. Close et al. [16] and Khistyaev et al. [15] presented structures for ionized hydrated thymine up to $n=3$. They used the lowestenergy $\mathrm{T}\left(\mathrm{H}_{2} \mathrm{O}\right)_{n}$ structures as the starting points for their $\mathrm{T}^{+}\left(\mathrm{H}_{2} \mathrm{O}\right)_{n}$ structure optimization. This approach is entirely reasonable for assessing the ionization energies of neutral clusters (the main aim of their work) but it does not necessarily consider the entire phase space of conformations accessible following ionization several $\mathrm{eV}$ above threshold, as occurs in the present MPI experiments (compare the ionization thresholds in Table 1 with $11.27 \mathrm{eV}$ shared between the excited cluster ion, the released electron, and any neutral dissociation products in 2-photon ionization at $220 \mathrm{~nm})$. Therefore, while their $\mathrm{T}^{+}\left(\mathrm{H}_{2} \mathrm{O}\right)$ (and $\mathrm{T}^{+}\left(\mathrm{H}_{2} \mathrm{O}\right)_{2}$ for Khistyaev et al. [15]) geometries match the present result (Fig. 3) it is not very surprising that their optimized geometries differ from ours at $n=3$ (Fig. 4). Indeed, the present lowest-energy $\mathrm{T}^{+}\left(\mathrm{H}_{2} \mathrm{O}\right)_{n}$ conformers (Figs. 3-5) all differ significantly from their neutral counterparts at $n=2-4$ (with at least one major rearrangement of a water molecule). 


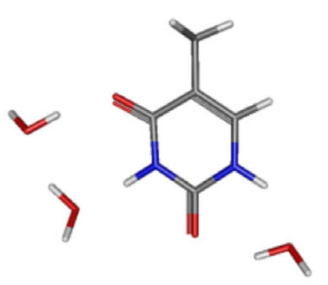

$\mathrm{T}\left(\mathrm{H}_{2} \mathrm{O}\right)_{3}$

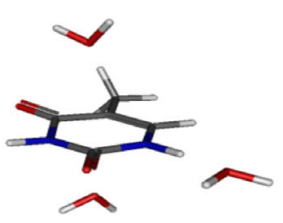

4, $\Delta \mathrm{E}=39 \mathrm{meV}$

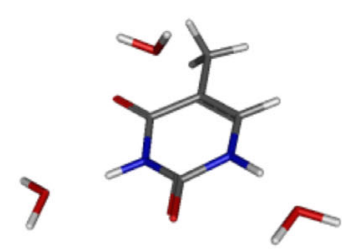

$\mathrm{T}^{+}\left(\mathrm{H}_{2} \mathrm{O}\right)_{3}, 1$

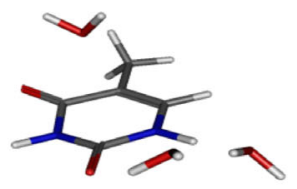

$5, \Delta \mathrm{E}=42 \mathrm{meV}$

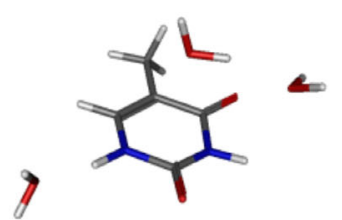

2, $\Delta \mathrm{E}=8 \mathrm{meV}$

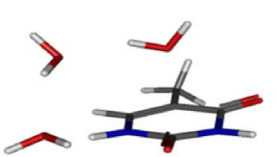

6, $\Delta \mathrm{E}=51 \mathrm{meV}$

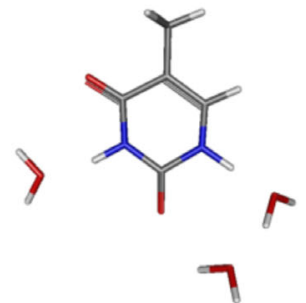

3, $\Delta \mathrm{E}=22 \mathrm{meV}$

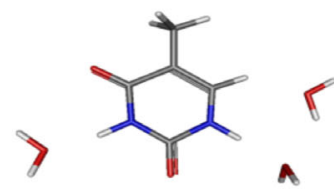

7, $\Delta \mathrm{E}=69 \mathrm{meV}$

Fig. 4. Structures of the lowest-energy conformers of $\mathrm{T}\left(\mathrm{H}_{2} \mathrm{O}\right)_{3}$ and $\mathrm{T}^{+}\left(\mathrm{H}_{2} \mathrm{O}\right)_{3}$ (numbered 1-7), optimized at the MP2/6$31+\mathrm{g}(d, p)$ level. Relative $\mathrm{T}^{+}\left(\mathrm{H}_{2} \mathrm{O}\right)_{3}$ conformer energies $(\Delta E$, zero-point vibrational energy corrected) are indicated.

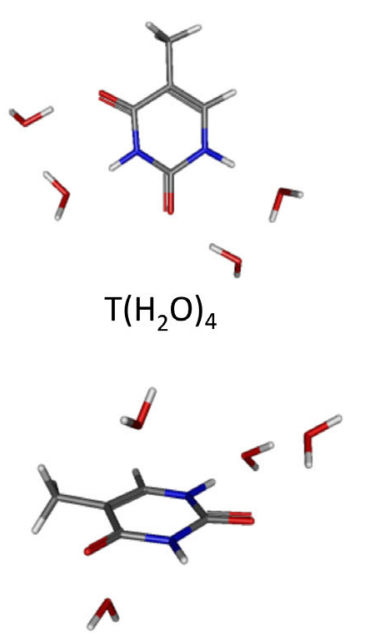

4, $\Delta \mathrm{E}=39 \mathrm{meV}$

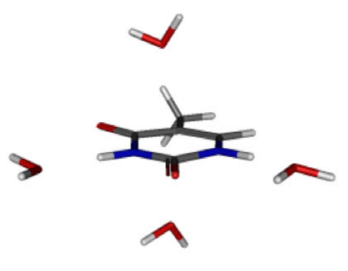

$\mathrm{T}^{+}\left(\mathrm{H}_{2} \mathrm{O}\right)_{4}, 1$

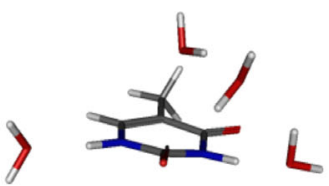

5, $\Delta \mathrm{E}=51 \mathrm{meV}$
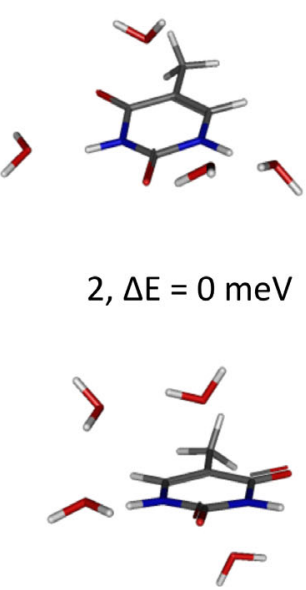

6, $\Delta \mathrm{E}=57 \mathrm{meV}$

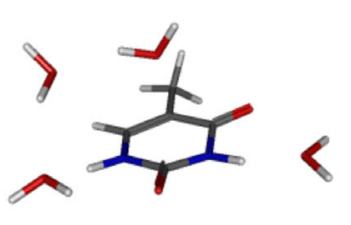

$3, \Delta \mathrm{E}=6 \mathrm{meV}$

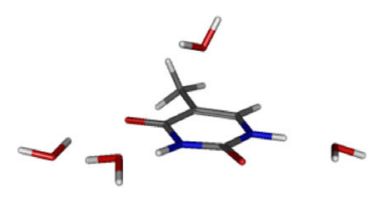

7, $\Delta \mathrm{E}=67 \mathrm{meV}$

Fig. 5. Structures of the lowest-energy conformers of $\mathrm{T}\left(\mathrm{H}_{2} \mathrm{O}\right)_{4}$ and $\mathrm{T}^{+}\left(\mathrm{H}_{2} \mathrm{O}\right)_{4}$ (numbered 1-7), optimized at the MP2/6$31+\mathrm{g}(d, p)$ level. Relative $\mathrm{T}^{+}\left(\mathrm{H}_{2} \mathrm{O}\right)_{4}$ conformer energies $(\Delta E$, zero-point vibrational energy corrected) are indicated.

The present and previous calculations of neutral hydrated thymine clusters support essentially planar hydrogen-bonded structures. While the most stable conformers of $\mathrm{T}^{+}\left(\mathrm{H}_{2} \mathrm{O}\right)$ and $\mathrm{T}^{+}\left(\mathrm{H}_{2} \mathrm{O}\right)_{2}$ also involve hydrogen bonding at both nitrogens, the present calculations show that alternative binding interactions and non-planar geometries are important in the cluster ions. $\Delta E$ is only $26 \mathrm{meV}$ between the $\mathrm{T}^{+}\left(\mathrm{H}_{2} \mathrm{O}\right)_{2}$ minimum and the lowestenergy structure with a water molecule located above the thymine $^{+}$ring (such molecules are referred to as ringbound in this discussion). This conformer $\left(\mathrm{T}^{+}\left(\mathrm{H}_{2} \mathrm{O}\right)_{2}\right.$ conformer 2 in Fig. 3) is consistent with stabilization via a charge-dipole interaction, while the present calculations indicate that the positive charge on the radical cation is mainly located at the carbon bound to the methyl group (referred to here as $\left.\mathrm{C}_{M}\right)$. For $\mathrm{T}^{+}\left(\mathrm{H}_{2} \mathrm{O}\right)_{3}$ and $\mathrm{T}^{+}\left(\mathrm{H}_{2} \mathrm{O}\right)_{4}$ (Figs. 4 and 5) ring-bound water molecules feature in the most stable conformers. Interestingly, the charge at $\mathrm{C}_{M}$ increases in conformers with two ring-bound water molecules $\left(\mathrm{T}^{+}\left(\mathrm{H}_{2} \mathrm{O}\right)_{3}\right.$ conformer 4 and $\mathrm{T}^{+}\left(\mathrm{H}_{2} \mathrm{O}\right)_{4}$ conformers 1,4 , and 6 ), while some additional charge appears at the methyl carbon. Such ring-bound conformers have been reported for hydrated benzene radical cations [45] but not for nucleobases. It is also noteworthy that there is no clear indication of a closed shell of four water molecules around the thymine radical cation to support Kim et al.'s [10] suggested interpretation of their metastable dissociation experiments

The calculated binding energies (BE) required for single $\mathrm{H}_{2} \mathrm{O}$ loss from $\mathrm{T}^{+}\left(\mathrm{H}_{2} \mathrm{O}\right)_{n}(n=1-4)$ are given in Figure 6 . The figure shows $\mathrm{BE}_{\text {min }}$ between the lowestenergy configurations of $\mathrm{T}^{+}\left(\mathrm{H}_{2} \mathrm{O}\right)_{n}$ and $\mathrm{T}^{+}\left(\mathrm{H}_{2} \mathrm{O}\right)_{(n-1)}+$ $\mathrm{H}_{2} \mathrm{O}$ as well as the average $\mathrm{BE}_{\text {ave }}$ of all possible evaporations (with minimum rearrangement). In both cases, 


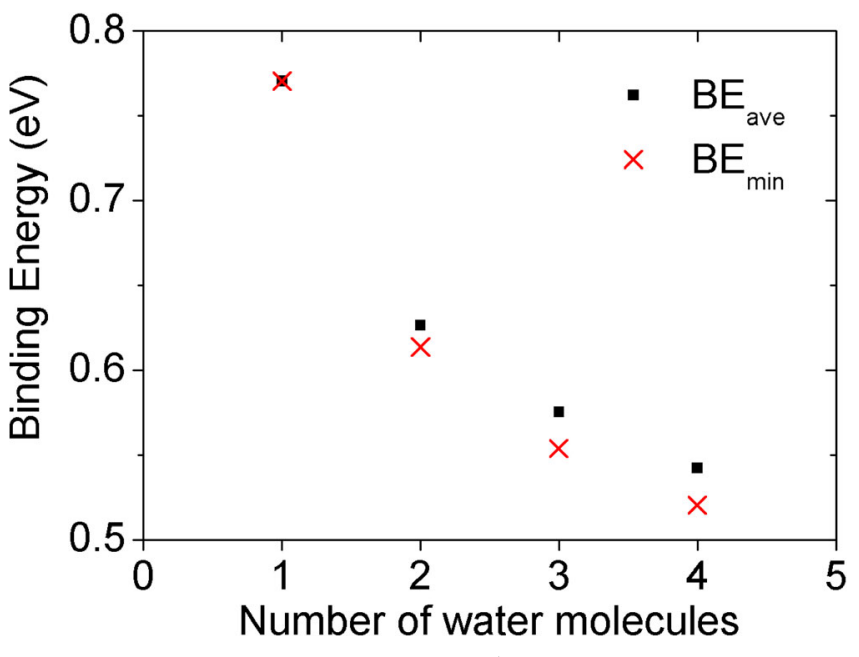

Fig. 6. Binding energies $(\mathrm{BE})$ of $\mathrm{T}^{+}\left(\mathrm{H}_{2} \mathrm{O}\right)_{n}$ calculated at the MP2 $/ 6-31+\mathrm{g}(d, p)$ level as a function of the number of water molecules bound to thymine. Average $\left(\mathrm{BE}_{\mathrm{ave}}\right)$ as well as minimum $\left(\mathrm{BE}_{\min }\right)$ binding energies are plotted (see the text for more detail).

BE decreases smoothly with $n$, with the greatest change (20\%) between $n=1$ and 2 . This is consistent with the general trend of increasing metastable $\mathrm{H}_{2} \mathrm{O}$ loss in the present experimental data, as well as in Kim et al.'s [10] results. In the range $n=2-4, \mathrm{BE}_{\min }$ falls by $6-10 \%$ and $\mathrm{BE}_{\text {ave }}$ by $6-8 \%$. These changes appear to be quite small in the context of the dramatic increase in metastable $\mathrm{H}_{2} \mathrm{O}$ loss observed in the present experiment across the same cluster ion size range (Tab. 2). This suggests that caution is required when attempting to associate the strength of metastable dissociation signals with cluster ion binding energies. In particular, we expect the number of available pathways for the loss of a molecule to play a role in determining the relative probability of metastable dissociation. This expectation is based on the premise that the vibrational energy in the cluster ion's intermolecular modes needs to be very close to a dissociation barrier in order for metastable dissociation to occur. The number of possible dissociation pathways, each with its own barrier potential, rises with cluster size so this will tend to increase the probability that a given vibrating cluster will meet the condition for metastable dissociation. Another reason for the much weaker metastable evaporation from $\mathrm{T}^{+}\left(\mathrm{H}_{2} \mathrm{O}\right)_{n}$ with $n \leq 3$ might be their lower internal energy after evaporation of a higher average number of water molecules compared to $n \geq 4$. Such a cooling effect has been observed in pure nucleobase clusters after ion impact ionization [46].

\section{Conclusions}

Metastable $\mathrm{H}_{2} \mathrm{O}$ loss from hydrated thymine radical cations has been observed in single-color MPI experiments; the second result of this kind in the literature. We have also calculated the most extensive set of optimized
$\mathrm{T}^{+}\left(\mathrm{H}_{2} \mathrm{O}\right)_{n}$ geometries to date (up to $n=4$ ). The binding energies for single water molecule removal fall with $\mathrm{n}$, broadly consistent with increasing metastable dissociation in the MPI experiments. The lowest energy $\mathrm{T}^{+}\left(\mathrm{H}_{2} \mathrm{O}\right)_{n}$ conformers differ significantly from their neutral counterparts for $n \geq 2$, with charge-dipole interactions playing important roles and no indication of preferential closedshell structures. Additional experimental and theoretical work (for example IR laser action spectroscopy in the fingerprint regions of $\mathrm{m} / \mathrm{z}$ selected cluster ions combined with quantum-chemical calculations of IR spectra) would be required to prove the existence of these interactions in hydrated thymine radical cations.

The authors are grateful for the expert technical support provided by F. Roberston, C. Hall, and their colleagues at the OU. The OU's financial and logistical support is also acknowledged. B. Barc is acknowledged for his important role in the design and construction of the experimental facility. S.E. acknowledges the support the British EPSRC through a Life Sciences Interface Fellowship (EP/E039618/1), a Career Acceleration Fellowship (EP/J002577/1), and a Research Grant (EP/L002191/1). The European Commission is acknowledged for a Marie Curie Intra-European Reintegration Grant (MERG-CT-2007-207292). S.E. and J.-C.P. are grateful to the steering committee of the EU/ESF COST Action XLIC (CM1204) for funding a Short-Term Scientific Mission in December 2014. The CNRS is acknowledged for a PICS Grant (07390) supporting the collaboration between CIMAP/GANIL and the OU. P.L.V. acknowledges the Portuguese National Funding Agency FCT-MCTES through Grant UID/FIS/00068/2013.

\section{Author contribution statement}

Rahul Pandey and Michal Ryszka performed the experiments. Mathieu Lalande and Jean-Christophe Poully worked on the calculations. Paulo Limão-Vieira, Nigel J. Mason, Jean-Christophe Poully and Samuel Eden interpreted the results and wrote the manuscript.

Open Access This is an open access article distributed under the terms of the Creative Commons Attribution License (http://creativecommons.org/licenses/by/4.0), which permits unrestricted use, distribution, and reproduction in any medium, provided the original work is properly cited.

\section{References}

1. V.G. Stavros, J.R.R. Verlet, Ann. Rev. Phys. Chem. 67, 211 (2016)

2. I. Hunig, C. Plutzer, K.A. Seefeld, D. Lowenich, M. Nispel, K. Kleinermanns, Chem. Phys. Chem. 5, 1427 (2004)

3. A.M. Rasmussen, M.C. Lind, S. Kim, H.F. Schaefer, J. Chem. Theory Comput. 6, 93 (2010)

4. Y. Nosenko, M. Kunitski, B. Brutschy, J. Phys. Chem. A 115, 9429 (2011) 
5. B. Barc, M. Ryszka, J.C. Poully, E. Jabbour Al Maalouf, Z. El Otell, J. Tabet, R. Parajuli, P.J.M. Van Der Burgt, P. Limão-Vieira, P. Cahillane, M. Dampc, N.J. Mason, S. Eden, Int. J. Mass Spectrom. 365, 194 (2014)

6. R.E. Continetti, Int. Rev. Phys. Chem. 17, 227 (1998)

7. R.G. Cooks, J.H. Beynon, R.M. Caprioli, G.R. Lester, Metastable Ions (Elsevier, Amsterdam, 1973)

8. E. Bruzzi, G. Raggi, R. Parajuli, A.J. Stace, J. Phys. Chem. A 118, 852 (2014)

9. S. Ishiuchi, M. Sakai, K. Daigoku, K. Hashimoto, M. Fujii, J. Chem. Phys. 127, 234304 (2007)

10. N.J. Kim, Y.S. Kim, G. Jeong, T.K. Ahn, S.K. Kim, Int. J. Mass Spectrom. 219, 11 (2002)

11. J. Jose Serrano-Perez, R. Gonzalez-Luque, M. Merchan, L. Serrano-Andres, J. Phys. Chem. B 111, 11880 (2007)

12. K. Khistyaev, A. Golan, K.B. Bravaya, N. Orms, A.I. Krylov, M. Ahmed, J. Phys. Chem. A 117, 6789 (2013)

13. A. Golan, K.B. Bravaya, R. Kudirka, O. Kostko, S.R. Leone, A.I. Krylov, M. Ahmed, Nat. Chem. 4, 323 (2012)

14. R.H. Duncan Lyngdoh, H.F. Schaefer, Acc. Chem. Res. 42, 563 (2009)

15. K. Khistyaev, K.B. Bravaya, E. Kamarchik, O. Kostko, M. Ahmed, A.I. Krylov, Faraday Discuss. 150, 31 (2011)

16. D.M. Close, C.E. Crespo-Hernández, L. Gorb, J. Leszczynski, J. Phys. Chem. A 112, 4405 (2008)

17. B. Barc, M. Ryszka, J. Spurrell, M. Dampc, P. LimãoVieira, R. Parajuli, N.J. Mason, S. Eden, J. Chem. Phys. 139, 244311 (2013)

18. M. Ryszka, R. Pandey, C. Rizk, J. Tabet, B. Barc, M. Dampc, N.J. Mason, S. Eden, Int. J. Mass Spectrom. 396 48 (2016)

19. P. Colarusso, K. Zhang, B. Guo, P.E. Bernath, Chem. Phys. Lett. 269, 39 (1997)

20. Y. Ibrahim, R. Mabrouki, M. Meot-Ner, M.S. El-Shall, J. Phys. Chem. A, 111, 1006 (2007)

21. M.J. Frisch, G.W. Trucks, H.B. Schlegel, G.E. Scuseria, M.A. Robb, J.R. Cheeseman, G. Scalmani, V. Barone, B. Mennucci, G.A. Petersson, H. Nakatsuji, M. Caricato, X. Li, H.P. Hratchian, A.F. Izmaylov, J. Bloino, G. Zheng, J.L. Sonnenberg, M. Hada, M. Ehara, K. Toyota, R. Fukuda, J. Hasegawa, M. Ishida, T. Nakajima, Y. Honda, O. Kitao, H. Nakai, T. Vreven, J.A. Montgomery, Jr., J.E. Peralta, F. Ogliaro, M. Bearpark, J.J. Heyd, E. Brothers, K.N. Kudin, V.N. Staroverov, R. Kobayashi, J. Normand, K. Raghavachari, A. Rendell, J.C. Burant, S.S. Iyengar, J. Tomasi, M. Cossi, N. Rega, J.M. Millam, M. Klene, J.E. Knox, J.B. Cross, V. Bakken, C. Adamo, J. Jaramillo, R. Gomperts, R.E. Stratmann, O. Yazyev, A.J. Austin, R. Cammi, C. Pomelli, J.W. Ochterski, R.L. Martin, K. Morokuma, V.G. Zakrzewski, G.A. Voth, P. Salvador, J.J. Dannenberg, S. Dapprich, A.D. Daniels, O. Farkas, J.B. Foresman, J.V. Ortiz, J. Cioslowski, D.J. Fox, R.A. Gaussian 09, Gaussian, Inc., Wallingford, CT, 2009
22. H.W. Jochims, M. Schwell, H. Baumgärtel, S. Leach, Chem. Phys. 314, 263 (2005)

23. L. Belau, K.R. Wilson, S.R. Leone, M. Ahmed, J. Phys. Chem. A 111, 756 (2007)

24. K.W. Choi, J.H. Lee, S.K. Kim, J. Am. Chem. Soc. 127, 15674 (2005)

25. S.K. Kim, W. Lee, D.R. Herschbach, J. Phys. Chem. 100, $793(1996)$

26. N.S. Hush, A.S. Cheung, Chem. Phys. Lett. 34, 11 (1975)

27. J.C. Lopez, M.I. Pena, M.E. Sanz, J.L. Alonso, J. Chem. Phys. 126, 191103 (2007)

28. J.C. Lopez, J.L. Alonso, I. Pena, V. Vaquero, Phys. Chem. Chem. Phys. 12, 1412 (2010)

29. N.J. Kim, Bull. Korean Chem. Soc. 27, 1009 (2006)

30. R. Mota, R. Parafita, A. Giuliani, M.J. Hubin-Franskin, J.M.C. Lourenco, G. Garcia, S.V. Hoffmann, N.J. Mason, P.A. Ribeiro, M. Raposo, P. Limao-Vieira, Chem. Phys. Lett. 416, 15 (2005)

31. M. Liu, T. Li, F.S. Amegayibor, D.S. Cardoso, Y. Fu, J.K. Lee, J. Org. Chem. 73, 9283 (2008)

32. J.J. Manura, D.J. Manura, Scientific Instrument Services Isotope Distribution Calculator, http://www.sisweb.com/ mstools/isotope.htm, 2016

33. H. Kang, K.T. Lee, B. Jung, Y.J. Ko, S.K. Kim, H. Kang, K.T. Lee, B. Jung, Y.J. Ko, S.K. Kim, J. Am. Chem. Soc. 124, 12958 (2002)

34. J. González-Vázquez, L. González, E. Samoylova, T. Schultz, Phys. Chem. Chem. Phys. 11, 3927 (2009)

35. Y.G. He, C.Y. Wu, W. Kong, J. Phys. Chem. A 108, 943 (2004)

36. M. Ligare, F. Siouri, O. Bludsky, D. Nachtigallova, M.S. de Vries, Phys. Chem. Chem. Phys. 17, 2433 (2015)

37. M. Etinski, C.M. Marian, Phys. Chem. Chem. Phys. 12, 4915 (2010)

38. M. Ryszka, Radiation Induced Processes in Biomolecules and Clusters in Controlled Beams, Ph.D. Thesis, The Open University (2016)

39. S. Heinbuch, F. Dong, J.J. Rocca, E.R. Bernstein, J. Chem. Phys. 126, 244301 (2007)

40. S. Kim, W. Lee, D. Herschbach, J. Phys. Chem. 3654, 7933 (1996)

41. K.E. Riley, P. Hobza, J. Phys. Chem. A 111, 8257 (2007)

42. M. Kabelác, P. Hobza, Phys. Chem. Chem. Phys. 9, 903 (2007)

43. S. Kim, S.E. Wheeler, H.F. Schaefer, J. Chem. Phys. 124, 204310 (2006)

44. D.M. Close, C.E. Crespo-Hernández, L. Gorb, J. Leszczynski, J. Phys. Chem. A 110, 7485 (2006)

45. O. Dopfer, Z. Phys. Chem. Int. 219, 12 (2005)

46. V. Vizcaino, J.C. Poully, J.Y. Chesnel, A. Domaracka, S. Maclot, A. Méry, J. Rangama, P. Rousseau, L. Adoui, B.A. Huber, Int. J. Mass Spectrom. 365, 181 (2014) 